\title{
Procreation, Footprint and Responsibility for Climate Change
}

\author{
Felix Pinkert ${ }^{1}$ (D) $\cdot$ Martin Sticker ${ }^{2}$ (D)
}

Received: 18 October 2019 / Accepted: 18 July 2020 / Published online: 4 August 2020

(c) The Author(s) 2020

\begin{abstract}
Several climate ethicists have recently argued that having children is morally equivalent to over-consumption, and contributes greatly to parents' personal carbon footprints. We show that these claims are mistaken, for two reasons. First, including procreation in parents' carbon footprints double-counts children's consumption emissions, once towards their own, and once towards their parents' footprints. We show that such double-counting defeats the chief purpose of the concept of carbon footprint, namely to measure the sustainability and equitability of one's activities and choices. Furthermore, we show that proposals to avoid double-counting have other unacceptable implications. Second, we show that the key arguments for a supposed moral equivalence of procreation and consumption overgenerate and lead to unacceptable consequences in many cases, such as for the work of doctors who save lives or enable procreation. Finally, we propose that rather than counting children's emissions towards their parents' carbon footprints, we should consider these emissions as part of the parents' carbon impact, i.e. the difference that their choices make to the overall global carbon emissions. It is from the perspective of impact that we should think about the ethics of procreation in an age of climate change.
\end{abstract}

Keywords Climate change $\cdot$ Carbon footprint $\cdot$ Procreation $\cdot$ Responsibility

What should you, as an individual, do to prevent catastrophic climate change? You could fly less, go vegan, or turn down the thermostat in your home. Your choices about these matters all make a significant difference to your personal carbon footprint. Yet, one choice seems to undo or outdo them all: Whether to have a(nother) child. After all, your child will cause immense emissions by eating, heating,

Felix Pinkert

felix.pinkert@univie.ac.at

1 Department of Philosophy, University of Vienna, Vienna, Austria

2 Department of Philosophy, University of Bristol, Bristol, United Kingdom 
travelling, etc. over her lifetime. Moreover, she might have children herself who will cause yet more emissions.

This line of thought has been popularized in newspaper pieces which have stated "Want to fight climate change? Have fewer children" (Carrington 2017), have wondered "Should We Be Having Kids In The Age Of Climate Change?" (Ludden 2016; Murtaugh 2015), and have even asked whether parents "are the worst climate sinners" (Kramper 2017) and whether "procreation is pollution" (Christinaz 2018). It has made an ongoing impact in climate change activism and advocacy as well, e.g. in movements such as the "BirthStrike" campaign group (see Elks 2019) ${ }^{1}$ or on-line recommendations for cutting your personal carbon footprint (e.g. Chandler 2019).

These provocative claims and questions are inspired and backed by a number of recent philosophical discussions of the climate ethical implications of procreation, which in turn draw on statistical analysis of how various activities and lifestyles impact the climate. Based on these calculations, several philosophers and statisticians have argued that if we want to fight climate change, then we should shift our focus from consumption to the yet undertheorized area of procreation. ${ }^{2}$ More specifically, they argue that having children is morally equivalent to morally problematic extensive consumption, and contributes immensely to parents' personal carbon footprints.

These claims, alongside some of their central presuppositions and implications, have not yet received the critical scrutiny they deserve. In this paper, we argue firstly that procreation should not be counted towards parents' carbon footprint. Secondly, if procreation is morally problematic from a climate ethics perspective, the reason for this cannot be a supposed analogy to consumption. Thirdly, those arguing for an obligation to limit individual procreation in response to climate change should re-frame their positions in terms of a new concept, carbon impact, rather than carbon footprint. In sum, we think that the dangers of climate change may well provide moral grounds for limiting procreation, but these grounds cannot be cashed out in terms of carbon footprint or a supposed analogy between procreation and consumption. Exploring alternative grounds is beyond the scope of this paper, but we provide the concept of carbon impact as a starting point for a conceptually more precise climate ethics of procreation.

Our proposal to reframe the debate has also a significant practical upshot, for the claim that procreation contributes enormously to parents' footprints creates a dilemma: On one horn of the dilemma, each person's permissible footprint is too small to accommodate the footprint increase that comes with having even just a

\footnotetext{
1 The idea that we should have fewer children to combat climate change is often conflated with the different idea that due to the negative impact climate change will have on the quality of life of future generations, it may be better not to have children for their own sake. This latter idea was recently given additional prominence by U.S. Representative Alexandria Ocasio-Cortez, but the public reaction to her quickly attributed to her the former idea (see Green 2019). A Fox News opinion piece was quick to associate her idea with coercive population control (see Ma 2019).

2 The seminal paper that quantifies the climate significance of procreation is Murtaugh and Schlax (2009). Their calculations are largely taken for granted by Conly (2016: 16), Earl et al. (2017), Hedberg (2019), Hickey et al. (2016), MacIver (2015), and Rieder (2016).
} 
single child per couple. It then follows that having even just one child per couple is morally wrong. This seems overly harsh-maybe we have strong reason to have fewer children, but, arguably, it should still be permissible to have at least one child per couple.

On the other horn of the dilemma having some number of children (for instance, one child per couple) is morally permissible. But then it seems that everyone is morally permitted to have an extremely large carbon footprint, namely so large as to include all the emissions that morally permissible procreation would produce. Then it follows that people without children are permitted extremely high consumption emissions that we would normally consider morally wrong. What started out as a philosophical project aimed at reducing emissions then turns into a permission for childless people to have unsustainably high footprints. ${ }^{3}$

The upshot of our paper, that the climate significance of procreation should not be understood in analogy to consumption, helps us avoid this dilemma, as procreation and consumption cannot simply be weighed against each other. It is then possible to hold that irrespective of our procreative choices, we are morally required to lower our consumption emissions as much as possible.

In Sect. 1, we show how a number of climate ethicists have recently conceptualized the ethical significance of procreation in terms of personal carbon footprint, have modelled procreative choices on consumption choices, or assume that procreation and consumption are morally comparable along the same metrics. In Sects. 2 and 3, we show how including emissions that result from procreation in parents' carbon footprints leads to objectionable double-counting of emissions. This doublecounting, we argue, can only be avoided by compromising the overall ethical point that the above ethicists want to make. In Sect. 4, we show how arguments on behalf of treating procreation as akin to footprint-increasing consumption overgenerate and lead to implausible implications. In Sect. 5, we diagnose the underlying problems with the idea that procreation and consumption are on a par, and indicate how we should instead think of the ethical significance of procreation for climate ethics. In Sect. 6, we explain in more detail how our position enables us to avoid the above dilemma, and how we can maintain that some procreation is permissible, but extensive consumption is not.

Four preliminary notes are in order here: First, the existing academic literature partly focuses on individual ethics and partly on the ethics of "population engineering" 4 , i.e. society-wide interventions to reduce the fertility rate and thereby a

\footnotetext{
3 In principle, such problematic trade-offs are not unique to procreation. If we hold that some kind of consumption, e.g. an average diet, is permissible, then we have to grant people a sufficiently large footprint allowance. If someone then opts for a lower footprint diet, they can use the footprint savings on other consumption, e.g. holiday flights. But procreation creates a particularly problematic trade-off, for two reasons: First, the premise that having at least one child is permissible is much harder to deny than the premise that some typical consumption choice, e.g. an average non-vegan diet, is permissible. Second, given the commonly assumed large footprint of having children, the extent of the trade-off is much larger than with trade-offs between ordinary consumption items.

4 This term was coined by Hickey et al. (2016), who propose a number of relatively non-coercive political means to reduce population growth.
} 
society's carbon footprint. In the present discussion, we focus on individual ethics. Second, we restrict our discussion to persons whose carbon emissions are relatively high in global terms, such as most people in affluent Western countries, and well-off people in developing and emerging economies. Third, we only consider people who are free to make their own procreative choices. Fourth, by "carbon emissions" we mean all greenhouse gas emissions, expressed in $\mathrm{CO}_{2}$ equivalents.

\section{Having children and carbon emissions}

When a high-carbon-emitter has a child, we can expect this child to follow similar high-emission consumption patterns as their parent. We can expect them to eat meat, drive cars, and use air travel to go on vacation. Furthermore, they may themselves have children, who in turn can be expected to engage in all of these activities. Had the high-carbon-emitter not had a child, then they would have prevented all of these future emissions. ${ }^{5}$ The choice of whether to have an (additional) ${ }^{6}$ child then makes a much larger difference than any typical consumption choice. ${ }^{7}$

To illustrate this point, suppose an 18-year-old commits to never owning a car and to cycling to work or taking public transportation instead. This choice may seem highly effective. But if she commits to having one child less than she would otherwise have, then this choice has a much larger impact: It prevents all of the emissions that the possible child would generate through their driving behaviour, plus all of their other emissions, plus all of the emissions of their children and subsequent descendants.

Recently, several authors have argued that, since procreative choices are of such significance for the climate, procreation immensely increases parents' carbon footprints, and is, in climate-ethical terms, equivalent to extensive consumption. For example, Young (2001: 183) argues that

it is inconsistent to believe that overconsumption is wrong or bad yet believe that having children is morally permissible, insofar as they produce comparable environmental impacts, are voluntary choices, and arise from similar desires.

In a more recent contribution, MacIver (2015: 107) writes

\footnotetext{
5 We assume that the decrease in emissions caused by people not having children would not be offset by increased consumption or procreation of others. Of course, there can be exceptional cases in which this assumption does not hold.

6 We leave the qualification "additional" henceforth implicit. Except when we discuss specifically the absolute number of children a person has, we are always concerned with the effect of having one more child.

7 Wynes et al. (2017: 6) provide an influential comparison of popular recommendations for individual emissions reductions with the measures that are in fact most effective, the list of which is topped by "having one fewer child."
} 
the standard dichotomy between "procreation" and "consumption" should be collapsed. [...] the impacts associated with procreation should be understood as part of the "ecological footprint" of parents[.]

and goes on to argue (MacIver 2015: 115) that procreation

can singlehandedly cancel out other efforts at mitigating environmental impacts.

Whilst in Young's and MacIver's work, these claims are given central importance and detailed defence, these claims are also endorsed elsewhere in the literature. In a yet more recent contribution to the debate, Travis Rieder argues for ethical limits to procreation based on a number of different rationales, such as agent-neutral reasons and justice (Rieder 2016: 26-32, 59-62), agent-specific reasons for not having children for their own sake (ibid.36), and green virtues (ibid. 57-9). Whilst his main arguments do not hinge on an analogy or moral equivalence between procreation and consumption, he nonetheless treats procreation and consumption as morally comparable along the same metric of carbon footprint:

having a child may make one responsible for as much as 9441 metric tons of $\mathrm{CO}_{2}$, while a flight from Washington, DC to Paris increases one's carbon footprint by approximately 1 metric ton (Rieder 2016: 40)

Rieder here summarizes the findings of Murtaugh and Schlax (2009: 18), who calculate the "carbon legacy" of procreative choices. They use these calculations to directly compare modifications of one's consumption behaviour, such as changing light bulbs, to the choice about having a child, and find the latter to massively overshadow the former. The same findings are also the foundation of Hedberg (2019: 6) claim that

procreation makes by far the largest contribution to one's individual GHG [greenhouse gas] emissions[.] ${ }^{8}$

Whilst all of the above authors endorse what we below label the "Footprint Thesis", the significance of this thesis differs for their respective arguments. Consequently, the implications and seriousness of our criticism of the Footprint Thesis also differs between these authors, and different authors will have different resources to respond to our proposed shift to the concept of carbon impact. We return to these differences when we present our alternative theoretical framework. For the time being, we take all of the above authors to endorse the

\footnotetext{
${ }^{8}$ Note that this is distinct from Hedberg (2018) earlier argument which appeals to a requirement to live with integrity. There, he assumes a duty to support a political collective solution to climate change, and argues that such a duty implies an individual duty to reduce one's personal greenhouse gas emissions.
} 
Footprint Thesis: A person's carbon footprint includes some or all of the consumption emissions of her children and subsequent descendants. ${ }^{9}$

\section{The Double-Counting Problem}

If we specify the phrase "some or all" in the Footprint Thesis, we can obtain different specifications of the thesis, which differ in what kind and how many of a descendant's emissions count towards her ancestors' footprints. Our first argument against the Footprint Thesis shows that any specification of the Footprint Thesis leads to objectionable double-counting of emissions. In Sect. 3, we will show that once we amend the Footprint Thesis to avoid double-counting, new, hitherto unrecognized, problems emerge for different specifications of the amended thesis.

\subsection{How Double-Counting Arises}

To see how the Footprint Thesis leads to double-counting of emissions, consider a stylised example of a very small world with only one couple and one child:

Small World: Abel and Berenice choose to have a child, Chantelle. Abel and Berenice each have lifetime emissions of $1000 \mathrm{t}$ of $\mathrm{CO}_{2}$ which arise from their consumption behaviour, and Chantelle's consumption behaviour likewise will cause $1000 \mathrm{t}$ of carbon emissions. Chantelle may herself have children in turn, but these children and subsequent descendants would live in a carbon-neutral future and not cause any net emissions.

Abel and Berenice's footprints contain their own consumption emissions, and, according to the Footprint Thesis, also some or all of Chantelle's consumption emissions. Let us assume, following Murtaugh and Schlax (2009), that all of her emissions count towards her parents' footprints, divided evenly between them. ${ }^{10}$ So Abel's lifetime carbon footprint is $1000 \mathrm{t}+500 \mathrm{t}=1500 \mathrm{t}$, and likewise for Berenice. Since the authors who endorse the Footprint Thesis do not explicitly discuss descendants' footprints, we read the Footprint Thesis as implicitly holding that Chantelle's consumption emissions also remain included in her own footprint, as the default position is that a person's consumption emissions count towards her own footprint. Chantelle's footprint then consists in the $1000 \mathrm{t}$ of consumption emissions over her lifetime.

\footnotetext{
9 While Young (2001) does not explicitly use the term "carbon footprint", he treats procreation as analogous to consumption. As consumption is the paradigmatic contributor to people's carbon footprints, it is fair to frame Young's view in terms of the Footprint Thesis. Moreover, our objection to Young's analogy in Sect. 4 can be framed without the use of the term "carbon footprint", by instead only talking about moral responsibility for using up resources.

10 Different splits between parents are conceivable. For example, in a patriarchal society in which men make all major family decisions, the male parents' share may be much larger. Our arguments hold irrespective of the specifics of the split.
} 
The Footprint Thesis leads to double-counting of Chantelle's emissions because, as Fig. 1 illustrates, the very same emissions that arise from Chantelle's consumption count once towards Chantelle's footprint, and once towards Abel's and Berenice's footprints.

Note that double-counting also happens if only some of Chantelle's emissions, for example, only her emissions before coming of age, also count towards her parents' footprints. It is then these emissions that are counted twice. The following discussion thus applies to all specifications of the Footprint Thesis-the only thing that changes are the specific amounts of double-counted emissions. ${ }^{11}$

Except for two brief mentions of double-counting (van Basshuysen 2018a, b), neither authors who endorse nor those who criticise the Footprint Thesis have hitherto appreciated that the thesis implies double-counting. But, as we show in the following, such double-counting is highly problematic for the Footprint Thesis.

\subsection{Why Double-Counting is Problematic}

That double counting of emissions is to be avoided is usually taken for granted without further discussion. For instance, Broome (2016: 163) contends that "[...] we must recognize one constraint [...] The total of emissions attributed to each person should be equal to the total actually emitted", which is incompatible with doublecounting (see below). Likewise, the 2015 Paris agreement explicitly requires that the agreement's parties avoid double-counting with regard to both emissions and emission-reduction. ${ }^{12}$ Note that double-counting is only problematic between footprintbearers of the same type, e.g. states, corporations, or individuals. Double counting between different types of footprint-bearers is not our concern here. For example, the fact that the footprint of a state includes emissions that also count towards the footprint of its citizens need not be a problem. But, apart from a brief discussion (van Basshuysen 2018b), it remains unclear why exactly double-counting is to be avoided.

The main problem with double-counting, we contend, is its incompatibility with the standard concept of carbon footprint as it is employed in current discussions concerning climate ethics and climate change mitigation. While there has been considerable debate about exactly which emissions count towards an individual's carbon footprint, ${ }^{13}$ the literature about carbon footprint and procreation, and, more generally, individual climate ethics, agrees that a person's carbon footprint measures how much $\mathrm{CO}_{2}$ and other greenhouse gases her activities add to the atmosphere. The reason we are especially interested in these emissions in the first place (and not e.g.

\footnotetext{
11 See Sect. 3 for a detailed discussion.

12 Paris Agreement, article 4, paragraph 13 (United Nations 2015): "In accounting for anthropogenic emissions and removals corresponding to their nationally determined contributions, Parties shall promote environmental integrity, transparency, accuracy, completeness, comparability and consistency, and ensure the avoidance of double counting."

13 For a survey of the wide variety of uses of the notion of a carbon footprint see Wiedmann and Minx (2008). See also Wright et al. (2011).
} 


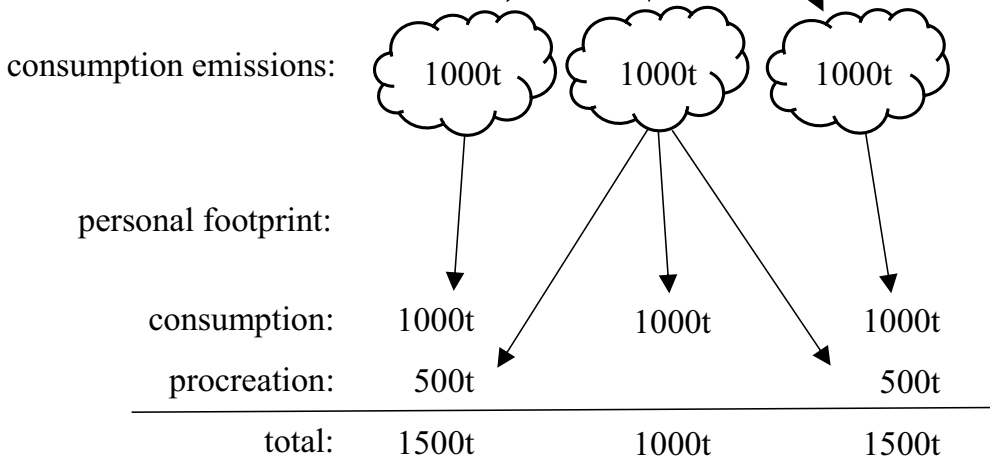

Fig. 1 Double-counting

in the amount of water vapour a person exhales) is that the atmosphere's capacity to safely absorb carbon emissions is limited and currently over-used. Carbon footprint thus measures how much of this limited absorption capacity of the atmosphere a person is using up. ${ }^{14}$

Additionally, the concept of carbon footprint also serves two practical functions: evaluation and guidance. First, we can evaluate the entirety of a person's carbon footprint with regard to its sustainability and equity: How does the amount of emissions associated with the person's activities compare to the maximum per capita emissions that are consistent with a sufficiently ambitious emissions reduction path for humanity as a whole? This question is answered e.g. by some carbon footprint calculators, which contextualise and interpret the absolute amount of emissions by making claims such as "If everyone lived like you, we would need four planets."

Second, a breakdown of a person's carbon footprint by activities offers her specific guidance about how she can reduce her carbon footprint. For example, such a breakdown could indicate that she avoidably causes a lot of emissions through her vacation travels.

\footnotetext{
14 The metaphor of "footprint" itself also implies a reference to a limited resource. The concept of carbon footprint is derived from the more inclusive notion of ecological footprint (Wright et al. 2011: 61), which is measured in the productive land area needed to sustain a particular activity. This measure is directly related to an overall resource limit, since the overall productive land area on Earth is limited.
} 
Implicit in the measurement, evaluation, and guidance functions is the idea that a person is morally responsible for her carbon footprint: She is answerable for her resource usage, and may be morally required to reduce it.

Authors who endorse the Footprint Thesis are most plausibly interpreted as using the standard concept of carbon footprint. After all, they do not say anything to the contrary or introduce a new and stipulative meaning of the term "carbon footprint". Furthermore, they evaluate the emissions associated with procreative choices against the backdrop of massive over-use of the atmospheric absorption capacity, which is exactly the framework in which the standard concept of footprint functions. Finally, those authors who treat procreation and consumption as analogous because both supposedly use up, "appropriate" or "claim" limited resources (see for instance MacIver 2015: 113-115) explicitly use the standard concept of footprint, as they are concerned with using up or appropriation of finite resources as their paradigm for behaviour that affects the climate.

Unfortunately for authors who endorse the Footprint Thesis, though, the doublecounting of emissions implied by the thesis is at odds with the very same measurement and evaluation functions of the standard concept of carbon footprint that is at the heart of the thesis.

First, due to double-counting, Chantelle's consumption emissions count both towards her parents' carbon footprints and towards her own footprint. This implies that her parents' procreative choices use up a certain part of the atmosphere's absorption capacity, and that Chantelle's consumption uses up the same part again. But the same part of a resource can't be used up twice. Hence the double-counting implied by the Footprint Thesis is inconsistent with the function of carbon footprint as a measure of how much of a limited resource we use up.

This conflict with the measurement function of carbon footprint also means that, contrary to the constraint that the "total of emissions attributed to each person should be equal to the total actually emitted" (Broome 2016: 163), the sum-total of the footprints of a society's members does not measure how much the society uses up: Assume that in Small World, the atmosphere's remaining absorption capacity is 3000 t. Abel's, Berenice's, and Chantelle's consumption each cause 1000 t of emissions, and there are no other emitters. According to the assumed specification of the Footprint Thesis, Abel and Berenice each have a footprint of $1500 \mathrm{t}$, which doublecounts $2 \times 500$ t of emissions that are also included in Chantelle's footprint. When we now add up all carbon footprints, we end up with a societal carbon footprint of $2 \times 1500 t+1000 t=4000 t$, which would imply that the three agents together use up $4000 \mathrm{t}$ of the Earth's absorption capacity and hence over-use. But they don't-they only use up $3000 \mathrm{t}$. Furthermore, we also end up with the absurd implication that the addition of Chantelle, a person who consumes just as much as Abel and Berenice, increases the per capita emissions in their society, namely from $1000 \mathrm{t}^{\text {to }} 1333 \mathrm{t}^{15}$

\footnotetext{
$15(1500 \mathrm{t}($ Abel $)+1500 \mathrm{t}($ Berenice $)+1000 \mathrm{t}($ Chantelle $)) / 3=1333 \mathrm{t}$. Note that Wynes et al. (2017) actually draw on this implausible implication, when they list having one fewer child alongside consumption reductions as means to reduce per capita footprints.
} 
Second, double-counting is at odds with the evaluative function of the concept of carbon footprint. To see this problem, let us evaluate Berenice's and Abel's footprints. In their society, their equal share in sustainable societal emissions is $3000 \mathrm{t} / 3=1000 \mathrm{t}$. Their footprints, according to the assumed specification of the Footprint Thesis, are $1500 \mathrm{t}$ each, so it appears that they individually over-use the atmosphere in an unsustainable manner. This individual over-use is not offset by any under-use on the part of Chantelle, as she uses exactly her equal share. However, if some agents exceed, and none under-use their equal share, it follows that the three agents collectively over-use the atmosphere. But by stipulation, they don't. Hence by modus tollens, the evaluation of Abel's and Berenice's behaviour as unsustainable is mistaken. This mistake arises because of double-counting, which is hence incompatible with the evaluation function of the standard concept of carbon footprint.

Since those accepting the Footprint Thesis typically rely on the measurement, evaluation, and guidance functions of the standard concept of carbon footprint, they cannot simply adopt a revisionary concept of carbon footprint that allows for double-counting. They thus would need to modify the thesis to avoid doublecounting. But, as we show in the next section, modifications geared towards preserving the measuring and evaluation functions compromise the guidance function of carbon footprint and introduce additional problems.

\section{The Splitting Problem}

To preserve the measurement and evaluation functions of the concept of carbon footprint, each unit of emissions must only be included in one person's footprint. Any unit of emissions of a person some generations down the family tree, say in generation G3, that we count towards the footprints of any of their presentday ancestors in generation G1 must thus not also be counted towards (a) that future person's footprint, or (b) the footprints of their intermediate ancestors in generation G2. A suitably amended version of the Footprint Thesis which avoids double-counting then reads:

Footprint Thesis*: A person's carbon footprint includes some or all of the consumption emissions of her children and subsequent descendants, and these emissions are excluded from the carbon footprints of the children and subsequent descendants.

This amended Footprint Thesis* avoids the double-counting problem, but the required splitting of emissions between people's footprints presents a new problem, the "splitting problem": No split of emissions gives us results for the footprints of descendants, present-day ancestors, and intermediate ancestors that are at least roughly in line with our intuitions about responsibility for carbon emissions and that also accord overwhelming importance to procreative decisions. 


\subsection{Maximum Footprint Thesis: Not Even Luxury Emissions Matter to Children's Own Carbon Footprint}

Consider again Murtaugh and Schlax's calculations, which provide the largest and most influential estimates for the footprint of having children. Their calculations assume that all of a future descendant's consumption emissions are to be counted towards the carbon footprints of all of her present-day ancestors, divided equally between them. ${ }^{16}$ To avoid double-counting, advocates of this position must further hold that none of these emissions are counted towards the carbon footprint of the descendant herself. Hence according to this "Maximum Footprint Thesis*", no matter how much the descendant consumes, her own footprint remains zero.

This implication is absurd, and it is completely at odds with the evaluation and guidance functions of the concept of carbon footprint. To see this point, consider again the two-generation case of Chantelle and her parents, but now placing them in the real world with its over-emission of $\mathrm{CO}_{2}$. Now assume that Chantelle engages in some conspicuous consumption that leads to clearly problematic luxury emissions, such as regular long-distance holiday flights. According to the Maximum Footprint Thesis*, the emissions associated with this behaviour feature in Abel's and Berenice's footprints, but do not appear in Chantelle's footprint at all. On this picture, while Abel's and Berenice's footprints maximally reflect the ethical significance of their procreative choices, Chantelle's footprint does not reflect the significance of her consumption choices at all. It thus cannot be the basis for evaluating her problematic behaviour, and cannot be used to guide her towards ways to reduce emissions, namely by reducing her luxury emissions. ${ }^{17}$

\subsection{More Moderate Splits: Hardship and Subsistence Emissions Remain Invisible}

Anyone who accepts the Footprint Thesis clearly would reject this absurd implication of the Maximum Footprint Thesis*. And indeed, some advocates of the Footprint Thesis explicitly propose to instead count only part of a child's emissions towards her parents' footprints. However, these proposals are still beset with problems.

Consider one of MacIver's (2015: 116) moderate proposals, namely that only hardship and subsistence emissions get handed down from descendants to ancestors. Hardship emissions are emissions that an agent can avoid, but avoiding them

\footnotetext{
16 Splitting between present-day ancestors is necessary in order to avoid double-counting within this generation, which would occur if each ancestor received $100 \%$ of the descendant's consumption emissions. Murtaugh and Schlax do advocate such a split, but they are not aware of the problem of double-counting between different generations. Note that Young's argument for the Footprint Thesis, which relies on the foreseeable consequences of procreation, might support a more radical and even more problematic "split" in which $100 \%$ of descendants' emissions get counted towards each parent. This is because up to a certain point each parent (usually) could have unilaterally decided against bringing a new person into existence.

17 van Basshuysen (2018b) similarly observe that it is implausible to attribute the emissions of optional consumption decisions of grown-up children to their ancestors rather than themselves.
} 
is very difficult and would lead to hardship for the agent. Subsistence emissions are impossible for an agent to avoid if she is to live a minimally decent life. Since both types of emissions are hard or impossible for the descendant to avoid, so the argument goes, it makes sense to attribute these emissions to the parents. After all, by not procreating, they could have readily averted the situation in which their descendant can hardly avoid causing these emissions.

However, the implications of excluding these emissions from the descendant's footprint are highly problematic. Consider first hardship emissions: Suppose that it is possible, but financially very difficult, for Chantelle to improve the insulation of her home. Due to the associated hardship, she may not be required to make this sacrifice. But her footprint should still show her that this supererogatory sacrifice is a way for her to reduce her emissions, and that she thus has some reason to make the sacrifice. Hence, if we exclude hardship emissions from her footprint, then her footprint can no longer guide her to the full range of possible emissions reductions that she has reason to make.

Now consider subsistence emissions. As avoiding these emissions is not a realistic option for Chantelle, it may seem unproblematic to exclude these emissions from her carbon footprint. But this impression is mistaken: Suppose that Chantelle needs to emit $2 \mathrm{t}$ of $\mathrm{CO}_{2}$ a year for using her car for local transport, since there is no other way for her to get to work and buy groceries. Individually, she cannot avoid these emissions without forgoing a minimally decent life, but this does not mean that she is off the hook: The social structures which make such high transport emissions necessary can, and should, be changed through collective action. Chantelle can advocate for such collective action through exercising her vote, writing to her political representatives, and otherwise participating in the public debate. For this reason, it is important that Chantelle can see the unavoidable $2 \mathrm{t}$ of transport emissions in her footprint, as this shows her that there is a need for social change and engagement. By excluding subsistence emissions from her carbon footprint, the concept of carbon footprint fails to fully fulfil this guidance function.

Moreover, treating subsistence (and hardship) emissions differently from luxury emissions also has absurd implications for climate-friendly social change. Suppose that Chantelle's society can invest heavily in public transport. A common way to advocate for such change is to point out that it would help reduce the carbon footprint of people in Chantelle's society, as they are then less likely to drive. Yet, this reasoning would not apply if we assume a Footprint Thesis* according to which only subsistence emissions are included in people's footprints. This is because if the investment goes through, then the emissions from any remaining car journeys that Chantelle makes, say for mere convenience, would no longer qualify as subsistence, but instead as luxury emissions, and would now increase her footprint. The best that Chantelle can hope for from the investment in public transport is then to keep her footprint constant, namely, if she foregoes driving entirely. Investment in public transport would hence not reduce her footprint, and this means that concern for her footprint cannot motivate this climate-friendly social change. 


\subsection{More Moderate Splits: Procreation is Not that Significant}

More moderate specifications of the Footprint Thesis* can also not be attractive for anyone who aims to show that procreation is a nearly all-important contributing factor to parents' carbon footprint, and that procreative choices are hence of overwhelming importance from a climate ethics perspective. This is because more moderate specifications of the Footprint Thesis* fall far short of yielding the staggering numbers presented by Murtaugh and Schlax.

Take MacIver's (2015: 115f.) minimal proposal, namely that only subsistence emissions count towards parents' footprints. Most importantly, these emissions do not include emissions of subsequent generations, as having a child, important as it may be for many people, is not necessary for living a minimally decent life. This restriction blocks the main driver of Murtaugh and Schlax' calculations, namely the accumulation of emissions over many generations.

To estimate how much a child's subsistence emissions would increase her parents' footprint, we have consulted several carbon footprint calculators and selected the lowest-carbon options offered in all choices. According to the calculators that offer the most radical emissions-reducing options, someone who always chooses the lowest-emissions option will produce $1.4 \mathrm{t}$ of emissions annually. We here assume that the corresponding maximally-carbon-frugal lifestyle is the subsistence minimum. ${ }^{18}$ On top of this number, one may want to include base emissions for the upkeep of public infrastructure and services. For example, for the UK, the WWF estimates that these emissions amount to $3 t$ per year per person. Since infrastructure and services would be provided and maintained irrespective of whether a specific person exists or uses them, it is not obvious that they need to be included in a person's footprint. ${ }^{19}$ So let us assume a range of $1.4 \mathrm{t}-4.4 \mathrm{t}$ per year for subsistence emissions.

Now, assume that Chantelle will live for 80 years. She then produces 108$352 t$ of subsistence emissions, which increases Abel and Berenice's footprints by 54t-176t each. This footprint increase is one to two orders of magnitude smaller than the numbers provided by Murtaugh and Schlax (2009: 18), and having one child less consequently ranks comfortably alongside relatively non-disruptive measures such as increasing the fuel efficiency of one's car by $50 \%$, which saves some 148t (Murtaugh and Schlax 2009: 18). This moderate specification of the Footprint Thesis* thus fails to capture the supposedly overwhelming significance of procreative choices. We thus have to reject claims such as MacIver's contention that " $[h]$ owever we divide up responsibility for impacts, [...] procreative decisions are by far

\footnotetext{
${ }^{18}$ See, for instance, https://www.carbonfootprint.com/, http://footprint.wwf.org.uk/, https://coolclimat e.berkeley.edu/calculator. None of the calculators offer the option of going completely "off the grid" and living as a subsistence farmer or a hunter-gatherer in the forest, so we here still have a relatively generous notion of subsistence emissions.

19 They could be included as expected emissions, under the assumption that there is a tiny probability that one more person will lead to more provisions of public infrastructure and services. Under plausible assumptions, each person's expected emissions are her equal share in the overall base emissions. Cf. Kagan (2011: 15-27) and Singer (1980: 335-336) for more detailed discussion of structurally similar cases.
} 
the most ecologically significant decisions that individuals will make in their lives" (MacIver 2015: 117, emphasis ours). ${ }^{20}$

\subsection{Differentiating by Increasing Autonomy of Descendants}

That more moderate specifications of the Footprint Thesis* turn out not to yield huge numbers also applies to another initially promising way of splitting emissions between parents and children, namely, to increasingly count children's consumption emissions towards their own footprints as their autonomy develops.

Philippe van Basshuysen (2018a) offers the most recent example of such an "Autonomy Footprint Thesis*" (also considered in van Basshuysen 2018b). On his thesis, coming of legal age is the cut-off point before which all of the child's emissions count towards her parents' footprints, and none towards her own, and after which all emissions count towards her own footprint and none towards her parents'. ${ }^{21}$ Van Basshuysen arrives at an estimate of 45 tons of $\mathrm{CO}_{2}$ per parent, which is significantly lower than the amounts suggested by the advocates of the Footprint Thesis we have discussed so far (up to 9441 tons). It is even an order of magnitude lower than Murtaugh and Schlax' (2009: 18) "optimistic scenario" calculation of 562t, and is only about one-third of Murtaugh and Schlax' estimate of the footprint savings incurred by doubling the fuel efficiency of one's car. Hence, in van Basshuysen's picture, procreation does not emerge as a supremely important contributor to parents' footprints. ${ }^{22}$

The main reason for these relatively low numbers is that on the Autonomy Footprint Thesis*, the emissions caused by any grandchildren that a child has after having attained autonomy do not count at all towards her parents' footprints, as these emissions fall squarely into the responsibility of the then-autonomous child (van Basshuysen 2018b: 2). Yet, it is the emissions caused by subsequent generations that lead to the supposedly impressive increases in parents' footprints. Hence, if we divide emissions according to the child's autonomy, as long as parents make sure that their offspring do not procreate before they can autonomously make procreative choices, having a child is not one of the most significant contributors to parents' footprints.

Moreover, van Basshuysen's estimate is still too high, as the Autonomy Footprint Thesis* is prone to over-estimate the difference that having a child makes to parents' footprints. ${ }^{23}$ This is because this thesis would simply add the child's

\footnotetext{
${ }^{20}$ MacIver is mistaken to make this claim in the context of talking about carbon footprint. It may well be true in another sense, namely that of carbon impact (see Sect. 5).

21 Broome (2016: 163) also advocates a split according to autonomy. See Cripps (2016: 122) for critical discussion.

22 Van Basshuysen and Brandsted (2018b: 2) point this out as well.

23 Note that by using legal age as a single cut-off point, van Basshuysen further overestimates the supposed footprint of procreation, as he wrongly attributes to the parents the emissions the child autonomously causes before coming of legal age. For example, a teenager may cause emissions by eating meat when vegetarian options would be available. These emissions are autonomously caused, as teenagers are usually capable of making ethically informed decisions about their diet.
} 
non-autonomous consumption to her parents' footprints. This way of calculating footprints thus assumes that when having a child, the parents' own consumption remains unchanged. However, this assumption is mistaken: As many parents can attest, having a child makes a huge difference to their personal consumption. In contrast to emissions caused by the grown-up, financially independent child, the goods and services that cause childrearing emissions are financed by the parents. While the parents might receive financial support, e.g. in the form of tax credits, having a child typically comes at a significant net cost, and parents thus have to cut back on their personal consumption. Moreover, even very well-off parents for whom money is not an issue still have to adapt their lifestyles and consumption to some extent. For example, taking long-distance flights to go on a scuba diving vacation with a one-year-old is just not an option. By having a child, the parents therefore typically replace some of their personal consumption with childrearing expenses, which can reduce the net contribution that having a child makes to parents' footprints. ${ }^{24}$

Van Basshuysen applies the Autonomy Footprint Thesis* without factoring in such consumption replacement. He simply assumes that an infant causes additional emissions of about half the per capita emissions of her society. His calculations thus over-estimate the contribution of childrearing to parents' footprints, as if the parents had an additional half per-capita income to spend on the family's consumption.

The Autonomy Footprint Thesis* thus cannot capture the idea that having a child is supposedly of massive climate ethical significance. Moreover, if childrearing expenses replace particularly high-emission consumption, such as overseas vacations, then on the Autonomy Footprint Thesis*, having a child might even decrease parents' footprints - certainly not a conclusion that authors who subscribe to the Footprint Thesis would like to broadcast. ${ }^{25}$

\subsection{Splitting Between Generations of Ancestors}

On top of the splitting problem as discussed above, we should bear in mind that in order to avoid double-counting in the long-term, it is not enough to split emissions between descendants and their present-day ancestors. Instead, we must also refrain from counting the same descendants' emissions towards their present-day and intermediate ancestors. This need to avoid double-counting between generations leads to a further challenge for the Footprint Thesis.

Consider three generations, G1, G2, and G3. Murtaugh and Schlax count all of G3's emissions towards G1's footprints. But once we avoid double-counting, the resulting Maximum Footprint Thesis* doesn't leave any of these emissions to be counted towards the footprint of G2. G2's procreative choices, contrary to G1's,

\footnotetext{
${ }^{24}$ However, there is at least some evidence that parents' footprints might actually be higher than those of non-parents, because parents tend to prefer more convenient and time-saving but more carbon intensive options. See Nordström et al. (2020) comparison of the consumption-footprints of Swedish parents and non-parents.

25 We lack the data to estimate the extent of the consumption replacement effect, which anyhow might differ drastically depending on parents' budgets and prior consumption patterns.
} 
then do not affect their own footprints at all. The thesis then fails to capture the ethical significance of G2's procreative choices, and implausibly treats G1's and G2's similar procreative choices radically differently.

Those who want to hold onto the Footprint Thesis thus need to split emissions across generations of ancestors in a way that avoids double-counting and that treats like choices alike. These desiderata can easily be met by simply not counting emissions across more than two generations at all, e.g. if we only count children's nonautonomous or subsistence emissions towards parents' footprints. But, as we have seen, this comes at the cost of not yielding impressively high numbers for parents' carbon footprint. Such revised versions of the Footprint Thesis fail to establish that procreative decisions matter significantly more than all other climate-relevant decisions.

We have yet to see a specification of the Footprint Thesis* that counts emissions across several generations and fulfils the above desiderata. But even if the challenge of developing such a thesis is met, once we split emissions across generations, the resulting Footprint Thesis* will fail to reflect that by not having children, every generation can avoid all of subsequent descendant's emissions. It will thus fail to do what advocates of the Footprint Thesis typically are after, namely, highlighting the full significance of each generation's procreative choices.

\subsection{The Splitting Problem Summarized}

The standard concept of carbon footprint requires that we do not double-count emissions between individuals. Those wanting to hold onto the Footprint Thesis then need to adopt a specification of the Footprint Thesis* which avoids double-counting by splitting emissions between present-day ancestors, their descendants, and intermediate generations of ancestors. But all such specifications have implausible implications or fail to highlight the supposed enormous significance that our procreative choices have for the climate. This is no accident, but the result of two trade-offs that are built into the need to avoid double-counting: The more of a future person's consumption emissions we count towards her ancestors' footprints, the less this person's footprint reflects the climate significance of her own consumption choices. Likewise, the more of these emissions we count towards the footprints of present-day ancestors, the less do the footprints of intermediate generations reflect the significance of their procreative choices.

Any attempt to capture the supposed climate significance of procreation by means of the concept of carbon footprint is therefore fundamentally flawed. In the next section, we will review and reject the most explicit arguments brought forward in behalf of the Footprint Thesis. This discussion will enable us to diagnose more precisely what is wrong with the Footprint Thesis, and to point towards a better way of thinking about procreation and climate change. 


\section{The Alleged Analogy Between Consumption and Procreation}

Whereas many authors, such as Rieder and Hedberg, assume implicitly that we can think about procreation along the lines of consumption, Young (2001) and MacIver (2015) offer two explicit arguments for this claim. According to their arguments, there is no relevant moral difference between procreation and consumption (Young), or procreation is a form of appropriating resources in the same way as consumption is (MacIver). The most straightforward way to establish these claims is to argue that there is a strong analogy between consumption and procreation, such that we can treat them similarly for the purposes of climate ethics. This is, prima facie, a promising strategy, since it is already widely accepted that excessive consumption, or what Young (2001: 183) calls "eco-gluttony", can and should be criticised. If it can be established that procreation is sufficiently analogous to eco-gluttony to warrant the same negative appraisal, then it is plausible that procreation is, under current conditions, criticisable in many cases. In the following, we scrutinize and reject both authors' arguments for this analogy.

\subsection{Young: Consumption, Procreation, and Foreseeable Impact}

Young (2001: 183) argues that both consumption and procreation "are voluntary, arise from the same desires, and produce similar foreseeable, unintended environmental impacts". With regard to climate ethical considerations, both activities are on a par: They both contribute to a person's carbon footprint, with the important difference that procreation contributes much more.

However, Young's argument overgenerates: Applied across the board, the three conditions, foreseeability, voluntariness and similar motivation, imply that certain actions are analogous to consumption even though they have nothing to do with a person's carbon footprint. Consider the following case:

Roxanne is a brilliant ER surgeon who leads a low-consumption lifestyle. Over the course of her career, she saves many lives that would be lost without her well-above-average medical expertise. ${ }^{26}$

All three criteria that Young gives for the supposed parity of consumption and procreation also apply to Roxanne: If Roxanne has a young patient on her operating table who would die if it were not for her skilled intervention, it is foreseeable that this patient, if he lives, will cause emissions for many years and his emissions would not occur if he had died. There is also a good chance that the patient will have descendants, who will also cause emissions that would not otherwise have occurred. Roxanne also acts voluntarily, as she has the option of not saving him. Lastly, Roxanne might act for motives similar to those that lie behind consumption. After all, in order to establish the supposed analogy between procreation and consumption,

\footnotetext{
${ }^{26}$ Roxanne might also save many people whom every competent surgeon could have saved. What matters for our purpose is that she saved people who would have died if it weren't specifically for her intervention.
} 
Young must adopt a very broad conception of these motives: "the motives behind reproduction and overconsumption are often identical: cultural expectations, improved status, elevated self-esteem, increased happiness, or an altruistic desire to share with others" (ibid. 185). We do not need to discuss here whether Young's claims about motivation are just an ad hoc manoeuvre to make consumption and procreation appear more similar. What matters for us is that Young's stipulation also strengthens the analogy between consumption and Roxanne. Roxanne may save lives in order to conform to role expectations of her as a doctor, to gain social status or to elevate her self-esteem, her work may simply make her happy, or her work may be altruistically motivated. ${ }^{27}$

By Young's reasoning, Roxanne's actions are on a par with consumption decisions, and these emissions are to be included in Roxanne's footprint. Since Roxanne is very good at her job, by the time she retires, her footprint will be enormous and dwarf even extreme cases of overconsumption.

This is implausible. Roxanne's footprint should not include her patients' emissions after she saved them. To make this point apparent, recall that Roxanne's footprint measures how much atmospheric absorption capacity she uses up, and her footprint is supposed to help evaluate her behaviour and to guide her towards possible improvements. Implicit in all this is the claim that Roxanne is morally responsible for the emissions included in her footprint. Moreover, due to the need to avoid double-counting, any given unit of emissions can be included only in one person's footprint. By counting a given emission towards Roxanne's rather than someone else's footprint, we thus say that she uses up the respective absorption capacity of the atmosphere, and that she in particular has to answer for, justify, and potentially reduce these emissions.

Now suppose that Roxanne saves a patient who, to celebrate his recovery, takes a long-distance vacation flight, and that this was foreseeable for Roxanne. By Young's reasoning, these emissions have to be counted towards Roxanne's footprint, ${ }^{28}$ i.e. Roxanne uses up the respective absorption capacity, and she in particular is responsible for this. But this is implausible, because the emissions from the flight are primarily the patient's responsibility, and thus should count towards the patient's, and not Roxanne's, footprint. ${ }^{29}$

We anticipate two possible responses to our argument against Young's analogy. First, Young might respond by pointing out that since Roxanne, in her role as a

\footnotetext{
27 In Sect. 4.2 we argue that we should not consider motivations or intentions as a relevant factor in determining a person's footprint.

${ }^{28}$ By the same reasoning, the emissions might also have to be counted towards the patient's footprint. Thus, Young's argument would directly imply objectionable double-counting. Young could respond that the patient's behaviour satisfies the three conditions that establish an analogy with consumption more fully than Roxanne's act of saving the patient does, and that the emissions thus should count only towards the patient's footprint. However, children's consumption might satisfy these conditions more fully than their parents act of procreation does, and thus children's emissions should count towards their own, and not their parents' footprints. Hence, this response would undermine the very aim of Young's argument.

${ }^{29}$ Gheaus (2019: 9) briefly makes a similar point about the claim that parents are morally responsible for the emissions of their children.
} 
doctor, is morally obligated to do everything in her power to save her patient, she does not act voluntarily, strictly speaking. However, this response fails: Even though it would violate her role obligations if she did not help, it is still possible for her to decide not to help her patient, and she thus still acts voluntarily if she decides to help. Moreover, the claim that obligatory actions are not strictly voluntary has implausible implications for consumption that is necessary to fulfil our role obligations. For example, it would then turn out that flying to the deathbed of a faraway parent, or other carbon-intensive necessary means to discharge one's role obligations, are not voluntary, and not part of one's (or anyone's) footprint.

Second, Young might want to reject our claim that Roxanne does not have an enormously large footprint. He could, for example, argue that what the Roxanne case shows is that Roxanne does have an enormous footprint, but that she can justify this footprint because she incurred it when engaging in morally good or socially valuable actions, or in fulfilment of her role obligations, for which we want to make footprint allowances. ${ }^{30}$

However, this position has unacceptable implications for the footprint of Roxanne's patients: If Roxanne's footprint included (some or all of) her patients' future emissions, then, in order to avoid double-counting, these emissions cannot also count towards her patients' (or their parents') footprints. This has bizarre implications: Suppose that some of the emissions added to Roxanne's footprint are subtracted from her patients' footprints. A great way for us to reduce our carbon footprint would then be to drive recklessly, get into a nasty car accident, and have ourselves saved by Roxanne. We would then have a zero, or at least lower, carbon footprint for the rest of our lives, without having to change our lifestyles at all! This absurd implication would follow because some or all of what we emit would henceforth count towards Roxanne's footprint, since without her intervention these emissions would not have occurred. Similar implications follow if the emissions added to Roxanne's footprint are taken out of the footprints of her patients' parents.

To sum up: Young's argument for the Footprint Thesis overgenerates, as it implies that we should allocate a patient's future emissions to the ER surgeon who saved her, which has implausible implications for the footprints of the surgeon and the patient.

\subsection{Maclver: Procreation and Creating Claims on Resources}

MacIver (2015: 110) conceives of the common element between consumption and procreation in terms of claims we make to limited resources and how these claims impact the interests of others. He claims that

\footnotetext{
${ }^{30}$ In a footnote Rieder (Rieder 2016: 40, fn. 8) discusses the possibility of large but justified footprints: "Physicians who work for Doctors Without Borders presumably have a large carbon footprint as a result of their international travel; I would think that their relatively large contribution to climate change is justifiable in the way that flying from New York to Paris for a fancy lunch would not be". Note that Rieder only considers the emissions caused by the doctors' travels. He does not consider the most extensive climate impact of the physicians' work, namely, saving lives, nor does he provide reasons for not including this impact in the doctors' (justifiable) footprints.
} 
[I]nsofar as all people make claims to natural goods by virtue of existing, creating new people is functionally equivalent to creating new claims to natural goods (MacIver 2015: 113)

and

there is no morally relevant distinction between an individual claiming a large quantity of natural goods for her own personal use, and an individual claiming a large quantity of natural goods for the use of her offspring (ibid. 115).

To avoid counter-intuitive implications for Roxanne's footprint, MacIver needs to argue that Roxanne's actions do not lay claim to the resources that her patients will consume in the future. He could, for example, point out that it is indeed odd to say that Roxanne lays claim to the resources consumed by the people she saves-if she lays claim at all, she simply lays claim to the resources needed for medical procedures, and the patients then keep laying claims to resources for their consumption.

But this response is too quick, because an analogous point could be made about parents: They lay claims to resources for rearing a child, but they do not claim the resources the grown-up child will consume - it is the grown-up child who claims the resources. Hence, on a narrow reading of "laying claims" that gives the right result for Roxanne, making a claim for oneself is also different from creating or sustaining someone who can and will lay claims, and MacIver's argument does not fly. Alternatively, if we grant MacIver a wide conception of claiming resources, then it is difficult to see how it would not encompass both creating persons who lay claims and sustaining persons who lay claims. The analogy would then overgenerate.

In response, MacIver may argue that a doctor simply saves the patient and might not care whether the person, once she leaves the hospital, lives or dies, whereas parents (presumably) want their children to live long and prosperously, knowing full well that doing so will cause emissions. On this picture, future consumption and procreation are closely connected in a way that does not hold for the doctor's work.

However, we think this is not a decisive difference. After all, the Footprint Thesis is not about what we want to be the case or intend, but what emissions we in particular are responsible for. Suppose that I procreate, intending my child to only have a minimal impact on the climate, but this intention is frustrated as my child consumes as much as everyone else. I cannot excuse myself by saying that this is not what I intended, as long as it was foreseeable that an additional member of my society will emit roughly as much as everyone else. Likewise, MacIver cannot use intentions to differentiate between parents and Roxanne.

In addition, suppose, for the sake of argument, that intentions are relevant for the question of whether some emissions are included in one's carbon footprint. If Roxanne cares deeply about the long-term well-being of her patients after the medical procedure, then she would have an enormous carbon footprint compared to a colleague who couldn't care less if patients dropped dead once they left the hospital. It would then seem that Roxanne, like caring parents, is claiming resources (on behalf of someone else) whereas her colleague (all else being equal) is not. Furthermore, once we exclude double-counting, a patient (or her parents) implausibly would have a lower post-operation footprint merely in virtue of being saved by Roxanne rather 
than by Roxane's indifferent colleague. Since these are absurd implications, we should reject the assumption that it matters what one intends the saved or newly created person to do. If there is no further difference in how doctors and parents lay claim to resources, then MacIver's reasoning extends to cases like Roxanne, and thus overgenerates.

MacIver entertains another feature of procreation that might allow him to distinguish between procreation and saving lives. He points out that "new people have no interest in being brought into existence" (MacIver 2015: 114), and that

insofar as we have no role or interest in being brought into existence, at minimum the unavoidable impacts and claims associated with our existence should be understood as belonging to our parents - at least for the purposes of assigning responsibility or weighing entitlements (ibid. 116-7)

However, that "new people" have no interest in being brought into existence does not help MacIver's argument for the Footprint Thesis. ${ }^{31}$ Even if we accept this difference between procreation and Roxanne's work, MacIver's position would still have implausible implications in a different case:

Ivy is a retired IVF doctor who helped couples conceive who cannot have children without specialized medical intervention. Her help has been a necessary condition for thousands of conceptions and resulting births.

It follows from MacIver's reasoning that Ivy has an enormous footprint since her work is analogous to procreation: Ivy's work is a necessary contribution to bringing into existence claims of new people who have no prior interest in coming into the world, and thus Ivy's footprint should include some of these people's consumption emissions.

Just as in the case of Roxanne, this implication for Ivy's footprint is implausible. The point here is not that Ivy does socially valuable or morally good things which justify an enormous footprint. Instead, the appropriate verdict is that, contra MacIver, she does not have such an enormous footprint to begin with. Furthermore, as in the Roxanne case, counter-intuitive implications for Ivy's footprint are only one part of the problem: If we counted some or all of the emissions of an IVF-conceived baby towards Ivy's footprint, then, in order to avoid double-counting, these emissions cannot also be counted towards the baby's or her parents' footprints. It then bizarrely turns out that making oneself require IVF treatment for procreation is a great way to reduce one's family's footprint. Hence, even if MacIver can escape the overgeneration problem by differentiating Roxanne's case from procreation, he faces the same problem again in the case of Ivy.

In summary, the available rationales for the Footprint Thesis have implausible implications for the personal carbon footprint of doctors like Roxanne and Ivy. Yet,

\footnotetext{
31 Note also that, as we argued with regard to subsistence emissions in Sect. 3.2, according to the "minimum" of counting only "unavoidable impacts", procreation makes only a moderate contribution towards parents' footprints. Thus, MacIver's proposal fails to yield his desired conclusion, namely, that procreation is one of the most significant contributors to parents' carbon footprints.
} 
without these rationales, it is no longer clear why we should affirm the Footprint Thesis at all. This holds all the more considering that the Footprint Thesis faces the double-counting and splitting problems.

\section{Footprint and Impact}

We have shown that including procreation in parents' carbon footprints is bedevilled with problems, and the main arguments for doing so fail. Yet, we do concede that given the unsustainability of humankind's carbon emissions, climate ethics must address actions that bring yet more high-emitters into existence. Our arguments do not deny this, but only show that the hitherto undertheorized role of procreation in climate ethics should not be conceptualized in terms of carbon footprint or in analogy to consumption.

In response to our arguments, those who want to hold onto the Footprint Thesis may be tempted to reconceptualize the notion of carbon footprint in a way that would allow them to include procreation into parents' carbon footprint-for instance, by permitting double-counting. However, such a revised measure will cease to function as an easy-to-use, informative and already-established tool for individual decision making, personal lifestyle choices, social criticism, and policy making. We therefore suggest that those who want to highlight the significance of procreation drop the idea that procreation contributes to parents' footprints. Instead, they should avail themselves of a different concept: carbon impact.

While personal carbon footprint measures how much of the limited absorption capacity of the atmosphere a person uses up, carbon impact measures how much of a difference an activity makes to overall emissions. These two concepts overlap but can also come apart: Changing one's footprint often makes a difference to overall emissions. For example, if I drive a car, more $\mathrm{CO}_{2}$ is being emitted than would have been had I walked instead. But not all changes to one's footprint have a carbon impact: If I buy the last vegan burger in a cafeteria and thus the vegan in line behind me has to buy the beef option, then overall meat consumption and the resulting emissions remain constant. This holds even though my footprint is now lower than it would have been had I bought the beef option. Conversely, and crucially for the purposes of our argument, not all of your carbon impact features in your carbon footprint, as you can impact overall emissions in a multitude of ways that have nothing to do with you using up carbon absorption capacity. For example, you can convince others to consume more or less, vote for green or non-green parties, and save or fail to save someone's life. None of these actions plausibly feature in your personal carbon footprint, as you don't use up or preserve resources here. But these actions can make a big difference to overall emissions. We contend that procreation should be understood as part of parents' carbon impact that does not feature in their footprints.

Understanding procreation in terms of such "pure" carbon impact is promising because contrary to the notion of footprint, the notion of impact does allow for double-counting. This is so because impact is concerned with the difference one's actions make, not with the using up of resources. Two actions cannot use up the same resource twice, but both can be necessary conditions for a given emission to 
occur. More generally, carbon impact represents causal responsibility, which allows for several conditions to be necessary causes of a given effect, and can thus easily allow for double-counting. For example, if two assassins together kill a person, each secretly administering one component of a poison, then both were necessary to kill the victim. We can then say that both of them committed a murder, i.e. made a difference which intentionally and wrongfully cost someone her life, without having to say that two persons were murdered. Likewise, our great-grandchildren's emissions would not take place without their own actions as well as the procreative choices of their parents, their grandparents, and us. Carbon impact, as opposed to footprint, can capture this observation: We can count the entirety of our great-grandchildren's consumption emissions towards their own carbon impact and that of all of their ancestors, without mistakenly implying that these emissions happened multiple times.

Framing the significance of procreation in terms of carbon impact also avoids the problem of overgenerating that plagues the analogy between consumption and procreation. This is because mere difference-making is not enough to establish the particular moral responsibility implied by carbon footprint. We can accept that Roxanne and Ivy have high carbon impacts, without accepting the implausible implication that they in particular are using up the respective absorption capacity, and that they in particular are morally responsible for these emissions.

In this way the concept of carbon impact allows climate ethicists to capture the idea that through our procreative choices we are able to make an enormous difference to overall emissions-more so than through many other choices, including consumption choices. But note that, contrary to the supposed analogy to consumption, this position does not already establish that we have strong reasons to have fewer children. All we get at this point is that, insofar as overall lower carbon emissions are better for the climate, we have defeasible reasons to have fewer children. But these reasons need not be particularly strong, or they can be outweighed by other considerations or goods that an activity or choice would realize. For instance, Roxanne makes a large impact on the climate, but her actions are justified and morally unproblematic. $^{32}$

However, those who share the intuition behind the Footprint Thesis need not be content with such a minimal moral conclusion. After all, while speaking in terms of carbon impact does not entail further normative evaluations, it also does not preclude them, as the following example illustrates:

Honest Tony is a car salesman who specializes in selling cars to people who don't have a car and don't want one and would not buy one if it were not for Honest Tony's persuasiveness. Since Honest Tony is skilled at his trade, he convinces many individuals that they need a car. It is foreseeable for Tony that this leads to higher overall emissions, but it is not Tony himself who emits.

\footnotetext{
32 In contrast to Roxanne, Ivy's behaviour may well be problematic, e.g. on grounds that helping parents conceive isn't as morally weighty as saving the lives of already existing people. The framework of carbon impact allows detailed discussion of precisely such issues.
} 
Other people emit, but they would not have emitted had Tony not talked them into it.

We take it that for the sake of the climate (and other reasons) Tony ought not to be doing what he is doing, and that he (alongside his customers) is morally responsible for the additional emissions caused. This holds even though he himself might have a very modest footprint, for instance because he is a vegan who commutes to work by bike and is mortally afraid of air travel. Yet, Honest Tony has a high and morally problematic carbon impact.

Hence if authors switch to talking about carbon impact instead of carbon footprint in order to address the climate ethics of procreation, then they face the following challenge: Contrary to the concept of carbon footprint, the concept of carbon impact is morally much thinner. If their modified claims are to reveal strong climaterelated reasons against having children, then they have to provide convincing reasons for evaluating the carbon impact of having children similarly to that of Honest Tony's actions. If they wanted to make this case, then they have more work to do: they have to argue that, under current circumstances, having children (or more children than one or two) is similar to the behaviour of Honest Tony, or other actions with high and objectionable impact (e.g. promoting climate change scepticism), and is relevantly dissimilar from cases like Roxanne, whose actions have a high but justifiable carbon impact.

Our arguments against the supposed analogies between procreation and consumption show that there is no quick and easy way to establish that procreation (or procreation beyond one or two children) is morally objectionable because it is supposedly akin to consumption and blameworthy eco-gluttony. The answer to the question of whether and how much procreation is justifiable from a climate ethics perspective must be settled by a more nuanced debate, e.g. by asking which other cases of carbon impact procreation is analogous to (if any), and how we should judge these cases, or by developing different arguments that do not rely on such analogies to begin with. For example, towards the end of his book, Rieder (2016: 57-59) suggests that the same green virtues should inform both our consumption behaviour and our procreative choices, without necessarily considering these two areas of difference making to be analogous or equivalent. Note that he does not, however, discuss the differences and similarities between these two (and other) areas of difference making that might influence how green virtues are to be respectively exercised in these areas. This is not a debate that we can pursue here. What we hope to have established is that the concept of carbon footprint and the analogy between procreation and consumption is unsuitable for debating the climate ethics of procreation, and the debate can be more fruitfully conducted in terms of carbon impact.

One caveat should be noted here: The above examples of carbon footprint without carbon impact, and carbon impact without carbon footprint might suggest that individual climate ethics in general should focus exclusively on carbon impact. However, such a proposal would be premature: First, not all carbon impacts are impacts for which agents are morally responsible-Roxanne is a case in point. A climate ethics focused on impact has to differentiate between impacts for which agents are morally responsible, and those for which they are not. Among those impacts for 
which agents are clearly morally responsible are those impacts which are also part of agents' footprints, e.g. impacts arising from many cases of consumption. Thus, even in a climate ethics centered around the concept of impact, footprint would still play a prominent role. Second, even those parts of our carbon footprints that do not have an impact, as in the vegan burger case, are still morally relevant. It may be pointless for an agent to individually reduce these parts of her overall carbon impact, but having them included shows her the full amount of emissions associated with her activities, and can prompt her to support social change. In the vegan burger example, the agents could demand that more vegan options be provided.

\section{Consumption and Childlessness}

Let us return to the dilemma that we presented at the outset of this paper. Imagine the following case: Two friends travel to a reunion in a faraway place, one of them by train, and the other by plane. The first person, a frequent vacation flyer, contends that her lifestyle is no worse than that of the second, more ecologically minded, person. This is because contrary to him, she doesn't have children nor intends to ever have children.

Implicit in this defence of frequent vacation flights is the plausible assumption that it is permissible for anyone to have one or perhaps two children. That this is the case is widely accepted even by those who think that there are moral limits to procreation. For instance, Travis Rieder and Sarah Conly ${ }^{33}$ admit that interests in having children are often of a fundamental nature and can ground rights to have a child. ${ }^{34}$ If even more drastic population reductions than one-child families are required, then it may be required to multi-parent with more than two adults rearing a child (see Gheaus 2019). But given the common estimates for the supposed footprint of having a child, even with a ratio of e.g. six parents per child, the footprint allowance for parenting would still be very high, and we would hence still have to grant non-parents moral permission to engage in substantial additional, unsustainable consumption.

Those advocating or implicitly accepting the Footprint Thesis certainly do not aim to give anyone a pass on extensive consumption. Yet if we count procreation towards parents' footprints, then we have to hold that the train-travelling friend is permitted to have a carbon footprint large enough to contain the emissions that follow from having one (or maybe two) children. As we have seen above, on any specification of the Footprint Thesis that makes procreation a highly significant contributor to parents' footprints, such a footprint would have to be quite large. The frequent flier without a child (and anyone with fewer than the permissible number of children) can then consume very extensively without exceeding her permissible

\footnotetext{
33 Conly thinks that the contribution of overpopulation to environmental degradation justifies limiting procreation. Moreover, she assumes that reducing procreation via government regulations is more realistic than reducing consumption on a large scale (see especially Conly 2016: 17).

34 Yet, for both of them there is a threshold-after the first child in the case of Conly (2016: ch.2) and after the first or second child in the case of Rieder (2016: 59) — after which having another child ceases to be a fundamental interest.
} 
carbon footprint. She simply "spends" her permissible footprint allowance on vacation flights as opposed to procreation.

The Footprint Thesis can only avoid this implication by adopting an implausibly harsh position on procreation, namely that it is not permissible to have even one child - this is the second horn of the dilemma.

To avoid the dilemma, parents could be granted a larger permissible footprint than non-parents. However, this response requires highly contentious assumptions about the value of different conceptions of the good life. It also opens the possibility for a slippery slope: If we tailor permissible footprints to people's lifestyles or desires, then we could also grant a larger footprint allowance to people who long to travel just as much as other people long to have children. Furthermore, even if we tailored permissible footprints to people's preferences, so that people who would only procreate for "frivolous" reasons are not morally permitted to procreate (as advocated by Hedberg 2019: 18), this would still leave involuntarily childless people who strongly desire to have children with an enormous footprint allowance that they would be permitted to spend on consumption. ${ }^{35}$

By contrast, our proposal to evaluate procreation in terms of impact instead of footprint allows us to straightforwardly sidestep the dilemma. Since, in our picture, procreation does not increase parents' carbon footprint, we can hold that it is permissible to have one or two children without saying anything about permissible carbon footprints at all. Hence, we can then still hold that extensive consumption by people without children is impermissible. On this picture, whatever else one may want to say about the climate ethics of procreation, we are responsible for reducing our consumption emissions, irrespective of how many children we have. This is how it should be.

\section{Conclusion}

The idea that the emissions of one's children count towards one's personal carbon footprint has become very popular in climate ethics and popular discourse. Following the most prominent calculations, the idea is held to imply that having children is a highly significant contributor to parents' footprints, to the point of dwarfing the contribution of typical consumption choices.

Yet, as we have argued, this Footprint Thesis is wrought with serious problems: On the most common formulation, it implies hitherto largely unrecognised but highly objectionable double-counting of emissions towards parents' and children's footprints. If we avoid this problem by splitting children's emissions between children and parents, the Footprint Thesis has implausible implications for children's footprints, and also often does not yield the implication that having children is a highly significant contributor to parents' footprints. Moreover, we have argued that the arguments advanced on behalf of the Footprint Thesis, which aim to establish

\footnotetext{
35 See also Gheaus (2019: 9, 15f.) for arguments against such tailoring of permissible footprints to people's motivations for parenting.
} 
an analogy between procreation and consumption, have implausible implications in other cases, such as doctors saving lives or helping couples conceive children.

We conclude that we should reject the Footprint Thesis, and think about the climate ethics of procreation by means of a different concept: carbon impact. Carbon impact allows for double-counting, and does not imply an analogy and possible trade-off between procreation and consumption.

What do our arguments imply for the authors who endorse the Footprint Thesis? Evaluating the prospects for each individual position is well beyond the scope of this paper, so we here only give two initial conjectures: First, Rieder endorses the Footprint Thesis primarily in order to highlight the climate-related significance of procreation. Similar work can be done by pointing to the high carbon impact of procreation: It shows that there is something of potential moral significance here, even though it does not in itself show that there is something morally problematic. To support his normative and moral claims about procreation, Rieder then primarily uses a separate conceptual apparatus, involving agent-neutral and agent-relative moral reasons, justice considerations and green virtues. Rieder can thus accommodate our criticism of the Footprint Thesis by switching from footprint to impact. He would have to make clear that it is his specific moral considerations, not the extent of the carbon impact of procreation as such, that supports his normative conclusions. Furthermore, he loses some of the initial plausibility of his conclusions, which were supported by the Footprint Thesis. So, his specific moral considerations would not have the independent support of the Footprint Thesis, and have to suffice entirely on their own.

Second, in contrast to Rieder, Young and MacIver, as well as Hedberg, derive normative conclusions directly from their endorsement of the Footprint Thesis. They hence cannot simply change their conceptual framework and talk about carbon impact instead, because carbon impact does not have the normative content to yield their conclusions. They hence have to do additional work to investigate why the high carbon impact of procreation supposedly makes it morally problematic.

More generally, on the proposed framework of carbon impact, observing that procreation has a very high carbon impact does not itself imply anything about the permissibility of procreation. Our arguments thus map out the direction that future research in the climate ethics of procreation should take: an investigation into permissible and impermissible carbon impacts.

Acknowledgements Open access funding provided by University of Vienna. The authors are grateful for comments and feedback from Maike Albertzart, Simon Caney, Stephanie Collins, Garret Cullity, Säde Hormio, Nadine Köhne, James Camien McGuiggan, Kirsten Meyer, Serena Olsaretti, Edward Page, Stefan Riedener, Dominic Roser, Lukas Tank, and two anonymous reviewers, as well as audiences at Humboldt University of Berlin, the annual conference of the Society for Applied Philosophy at the University of Cardiff, the conference of the Society for Analytic Philosophy at the University of Cologne, Trinity College Dublin's Long Room Hub and the University of Oxford. We also thank Michael Eigner for research assistance.

Open Access This article is licensed under a Creative Commons Attribution 4.0 International License, which permits use, sharing, adaptation, distribution and reproduction in any medium or format, as long as you give appropriate credit to the original author(s) and the source, provide a link to the Creative Commons licence, and indicate if changes were made. The images or other third party material in this article 
are included in the article's Creative Commons licence, unless indicated otherwise in a credit line to the material. If material is not included in the article's Creative Commons licence and your intended use is not permitted by statutory regulation or exceeds the permitted use, you will need to obtain permission directly from the copyright holder. To view a copy of this licence, visit http://creativecommons.org/licen ses/by/4.0/.

\section{References}

Broome, John. 2016. A Reply to My Critics. Midwest Studies in Philosophy 40: 158-171.

Carrington, Damian. 2017. Want to Fight Climate Change? Have Fewer Children. The Guardian, 12 July 2017. https://www.theguardian.com/environment/2017/jul/12/want-to-fight-climate-change-havefewer-children.

Chandler, Craig K. 2019. How Family Size Shapes Your Carbon. Yale Climate Connections, 29 March 2019. https://www.yaleclimateconnections.org/2019/03/how-family-size-shapes-your-carbon-footp rint/.

Christinaz, Caroline. 2018. Procréer, c'est Polluer? Le Temps, 10 October 2018. https://www.letemps.ch/ opinions/procreer-cest-polluer.

Conly, Sarah. 2016. One Child. Do We Have a Right to More? Oxford: Oxford University Press.

Cripps, Elizabeth. 2016. On Climate Matters: Offsetting, Population, and Justice. Midwest Studies in Philosophy 40: 114-128.

Earl, Jake, Colin Hickey, and Travis Rieder. 2017. Fertility, Immigration, and the Fight Against Climate Change. Bioethics 31(8): 582-589.

Elks, Sonia. 2019. A New "Climate Strike”: Opting for No Children as Climate Fears Grow. Reuters, 13 May 2019. https://www.reuters.com/article/us-global-women-climatechange/a-new-climate-strik e-opting-for-no-children-as-climate-fears-grow-idUSKCN1SJ02Z.

Gheaus, Anca. 2019. More Co-parents, Fewer Children: Multiparenting and Sustainable Population. Essays in Philosophy 20(1): 2. https://doi.org/10.7710/1526-0569.1630.

Green, Miranda. 2019. Ocasio-Cortez: It's "Legitimate” to Ask If OK to Have Children in Face of Climate Change. The Hill, 25 February 2019. https://thehill.com/policy/energy-environment/43144 0-ocasio-cortez-in-face-of-climate-change-its-legitimate-to-ask-if-ok

Hedberg, Trevor. 2018. Climate Change, Moral Integrity, and Obligations to Reduce Individual Greenhouse Gas Emissions. Ethics, Policy, and Environment 21(1): 64-80.

Hedberg, Trevor. 2019. The Duty to Reduce Greenhouse Gas Emissions and the Limits of Permissible Procreation. Essays in Philosophy 20(1), Article 4.

Hickey, Colin, Travis Rieder, and Jake Earl. 2016. Population Engineering and the Fight against Climate Change. Social Theory and Practice 42(4): 845-870.

Kagan, Shelly. 2011. Do I Make A Difference? Philosophy \& Public Affairs 39: 105-141.

Kramper, Gernot. 2017. 20 BMW schädigen das Klima weniger als ein Baby. Stern, 16 July 2017. https ://www.stern.de/panorama/wissen/umweltstudie-20-bmw-schaedigen-das-klima-weniger-als-einbaby-7539938.html.

Ludden, Jennifer. 2016. Should We Be Having Kids In The Age Of Climate Change? National Public Radio, 18 August 2016. https://www.npr.org/2016/08/18/479349760/should-we-be-having-kids-inthe-age-of-climate-change $\mathrm{t}=1531494102278 \& \mathrm{t}=1567340224961$.

Ma, Ying. 2019. Alexandria Ocasio-Cortez's Latest Climate Fix - No Children for You. Fox News, 26 February 2019. https://www.foxnews.com/opinion/alexandria-ocasio-cortezs-latest-climate-fix-nochildren-for-you.

MacIver, Corey. 2015. Procreation as Appropriation. In Permissible Progeny? The Morality of Procreation and Parenting, ed. Sarah Hannan, Samantha Brennan, and Richard Vernon, 107-129. Oxford: Oxford University Press.

Murtaugh, Paul A. 2015. Paul Ehrlich's Population Bomb Argument Was Right. The New York Times, 8 June 2015. https://www.nytimes.com/roomfordebate/2015/06/08/is-overpopulation-a-legitimate -threat-to-humanity-and-the-planet/paul-ehrlichs-population-bomb-argument-was-right.

Murtaugh, Paul, and Michael Schlax. 2009. Reproduction and the carbon legacies of individuals. Global Environmental Change 19(1): 14-20. 
Nordström, J., J.F. Shogren, and L. Thunström. 2020. Do parents counter-balance the carbon emissions of their children? PLOS ONE 15(4): 0231105.

Rieder, Travis. 2016. Toward a Small Family Ethic: How Overpopulation and Climate Change are Affecting the Morality of Procreation. Berlin: Springer.

Singer, Peter. 1980. Utilitarianism and Vegetarianism. Philosophy \& Public Affairs 9: 325-337.

United Nations. 2015. The Paris Agreement. https://unfccc.int/sites/default/files/english_paris_agree ment.pdf.

van Basshuysen, Philippe. 2018. Reproductive Choices and Climate Change Part 1: can you reduce your emissions by having fewer children? LSE Philosophy Blog, 23 March 2018. http://www.lse.ac.uk/ philosophy/blog/2018/03/23/reproductive-choices-and-climate-change-1.

van Basshuysen, Philippe, and Brandstedt, Eric. 2018. Comment on 'The climate mitigation gap: education and government recommendations miss the most effective individual actions". Environmental Research Letters 13(4).

Wiedmann, Thomas, and Jan Christoph Minx. 2008. A Definition of Carbon Footprint. In Ecological Economics Research Trends, ed. Carolyn Pertsova, 1-11. Hauppauge: Nova Science Publishers.

Wright, Laurence, Simon Kemp, and Ian Williams. 2011. 'Carbon footprinting': towards a universally accepted definition. Carbon Management 2(1): 61-72.

Wynes, Seth, and Kimberley A. Nicholas. 2017. The climate mitigation gap: education and government recommendations miss the most effective individual actions. Environmental Research Letters 12: 8.

Young, Thomas. 2001. Overconsumption and Procreation: Are they Morally Equivalent? Journal of Applied Philosophy 18(2): 183-192.

Publisher's Note Springer Nature remains neutral with regard to jurisdictional claims in published maps and institutional affiliations. 